\title{
Appraisal of the General Studies (GST) Entrepreneurship Skills Acquisition Curriculum for University Undergraduates in Nigeria: Challenges and the Way Forward
}

\author{
Mary E.U. Ogah \\ Department of Educational Foundations, \\ Ebonyi State University, Abakaliki-Nigeria \\ Nnenna Orieoma Emesini \\ Department of Educational Foundations, \\ Ebonyi State University, Abakaliki-Nigeria
}

Doi:10.5901/mjss.2013.v4n7p137

\begin{abstract}
The study analyzed entrepreneurship skills acquisition content of GST curriculum for undergraduates in Nigerian Universities. Four research questions guided the study. The population of the study was all the three hundred level students of 2011/2012 academic session who were exposed to the entrepreneurial skill GST curriculum. A sample of 400 students was used for the study. A 52- itemed questionnaire was used to collect data from the respondents. The instrument was validated by two experts from GST unit, and one from Measurement and Evaluation, all from Ebonyi State University, Abakaliki. The instrument yielded a reliability coefficient of 0.72 using Cronbach Alpha method. The results from the responses were analyzed using mean scores and percentages. The study findings showed that the students could not properly identify the content of general entrepreneurship curriculum, and were not exposed to the practical aspect of the skills; hence the low percentage recorded for those who are ready to practice the skills. They equally agreed that they would face the enlisted challenges in the practice of the skills. Based on the findings of the study, recommendations were made.
\end{abstract}

Keywords: Appraisal; Entrepreneurship; Skills Acquisition; Curriculum; Entrepreneurship Education;

\section{Introduction}

The word "entrepreneur" is derived from a French root "entrepreudre" meaning, "to undertake" a go-between. The term entrepreneurship is viewed differently by different scholars, educators, researchers etc. Hisrich in Egwu, Ogbu, Ogunji, Oselebe and Ama (2011) describe entrepreneurship as a process of creating some thing different with value added and by devoting the necessary time, effort and resources. The authors further explain that the needed and necessary accompanying financial, psychological, mental, spiritual and social risks involved must be guaranteed. On the same vein, Dan'Azumi (2010) sees entrepreneurship as a process of identifying, developing and bringing a vision of life. Dakare, Osifila and Ogbjafor (2011)posit that entrepreneurship involve individual ability to turn idea into action, which includes creativity, innovation and risk taking, as well as the ability to plan and manage projects in order to achieve objectives.

Entrepreneurship education on the other hand, could be viewed as a way of teaching students how to acquire the necessary skills. Ekong and Williams (2006) sees entrepreneurship education as a process of teaching people how to acquire skills through the study of school subjects, and how to utilize those skills for self sustenance and self-reliance. 
From the different definitions, one can define entrepreneurship education as a process of teaching learners to acquire skills for self-reliance; to see opportunities where others could not, and to generate wealth and create employment. Skill acquisition according to Hornby (2006) is the ability to do something Onyekwelu (2005) describes skills acquisition as a job oriented kind of training with the ultimate goal of preparing people for the world of work in the society. It is a way of gaining ability to work well. Therefore entrepreneurship skills acquisition could be referred to as a way of equipping individuals with the necessary ability for production of necessary goods and services.

Entrepreneurship education is a new programme introduced by Nigerian University Commission (NUC) into Nigerian universities. According to Okojie (2011), the Federal Government in 2002 decided that entrepreneurship studies be injected into the curriculum of university education in Nigeria, and since then, it has been introduced as General Studies (GST). The objective was to empower students to be able to harness opportunities, and be self-reliant and become job-creators and not job-seekers. Entrepreneurship education tends to make the curriculum more functional. Functional curriculum, according to Esu (2010) is designed to teach students skills that will equip them to function as competent and accepted adults in the society. Izedonmi and Okafor (2010) reiterate that entrepreneurship education equips youths with passion and multiple skills to operate a successful business on their own.

Introduction of entrepreneurship education curriculum into Nigerian universities is timely especially now that the rate of graduate unemployment is rising on a geometrical progression. Adejimola and Tayo-Olajubutu (2009) observe that it is a common experience that about $80 \%$ of the graduates from Nigerian universities find it difficult to get employment every year. This is partly due to the curricula of the universities and other tertiary institutions which train students for white-collar jobs. Currently, national and regional policy thrusts like the National Economic Empowerment and Development Strategy (NEEDS) have engaged in advocacy trying to sensitize the youths by emphasizing on poverty eradication, employment generation, wealth-creation and public-private partnership. As a follow up, a number of initiatives like the National Poverty Eradication Programme (NAPEP), and the establishment of Small and Medium Enterprises Development Agency of Nigeria, (SMEDAN) were introduced (Osibanjo, 2006 and Okojie, 2008)). However, despite these efforts, the situation has not really changed. Adeyemi (2006) opine that the problem might be from the method of teaching the students. He point out that in developed economics, the education system emphasizes the trail of inquiry - discovery - application in teaching, and students are meant to perceive problems, (including societal problems) as challenges and opportunities that can be turned into goods and services of commercial value.

Entrepreneurship education has been introduced in the nation's university curricula for the past three years, and the first batch of entrepreneurial graduates are about to emerge. It is now pertinent to ascertain the journey so far; hence the need for the study based on the appraisal of the GST entrepreneurship skills acquisition curriculum for Nigerian universities, its challenges and the way forward.

\section{Statement of the Problem}

Functional education involves training youths in such a way that they would be independent, and contribute their own quota in national development. To the utmost dismay of concerned citizens of Nigeria, Universities in the country have been producing graduates who are still government job seekers, which in most cases are non-existent. This burden necessitated the introduction of entrepreneurship education in Nigerian universities, to make graduates self-reliant and employers of labour. This laudable vision that have been mounted in most Nigerian universities for about 3 years now has led the researchers to carry out a formative evaluation of the entrepreneurship programme in our universities, and thus seek to appraise the general studies entrepreneurship programme for undergraduate in Nigerian universities, challenges and the way forward. 


\section{Objectives of the Study}

The study sought to find out:

1. The extent the GST curriculum contents provides for the general entrepreneurship skills/trade;

2. The extent students were exposed to the specific entrepreneurship skill/trade;

3. Which of the entrepreneurship skills students are ready to practice after graduation for self-reliance, and

4. The extent the students have perceived the enlisted challenges as possible challenges in the practising of the skills/trade after graduation

\section{Research Questions}

The following research questions guided the study:

1. To what extent do GST curriculum contents provide for the general entrepreneurship skills/trade?

2. To what extent were you exposed to the specific skills/trade?

3. Which of the entrepreneurship skills/trade are you ready to practice after graduation for selfreliance? and

4. To what extent have you perceived possible challenges to practising the entrepreneurship skills/trade after graduation?

\section{Theoretical Framework}

Related theories to the study include that of Schumpeter (1934), who postulated that when the economy is in distress (as it is at present the world over), profit motivated entrepreneurs will innovate, create and invent new things, products and services, to stimulate productivity and job creation, thereby increasing wealth and profit. Drucken in Egwu et al (2011) in his theory, states that an entrepreneur sees opportunities everywhere others are blind, and maximizes them before others get there. Also, Shapiro quoted by Egwu et al (2011 postulates that an entrepreneur takes initiative, organizes some socio-economic mechanisms, adds value to existing products or technology, and accepts risk of failure. According to Egwu (2011) entrepreneurs rule the economics of their nations, and those nations with the highest number of innovators at any point in history are the ones that rule the world. Without innovations and inventors, new products, services and processes for the market will dry up, and the economy will collapse. These theories are related to this study in the sense that they all acknowledge entrepreneurship to be a quality of the human capital involved, and the prevailing economic situation.

\section{Methods and Procedures}

\subsection{Research Design:}

The study used a descriptive survey design to elicit information from respondents. According to Nworgu (2006) the descriptive survey design is most appropriate when a survey involves describing certain variables in relation to a given population.

\subsection{Population/Sample and Sampling Techniques:}

The area of study was Ebonyi State University, Abakaliki in Ebonyi State. The population for the study was $4,4703^{\text {rd }}$ year undergraduates who were exposed to GST entrepreneurial skills curriculum. The sample for 
the study was 400 drawn using stratified random sampling techniques from the seven faculties of the university.

\subsection{Instrumentation:}

A fifty-two (52) itemed questionnaire was used for data collection. The instrument was structured on a 5-point scale weighted thus: Very High Extent $(\mathrm{VHE})=5$ points; High Extent $(\mathrm{HE})=4$ points; Moderate Extent $(\mathrm{ME})=$ 3 points, Low Extent (LE) = 2 points and No Extent $(N E)=1$ point, with criterion mean of 3.00 . It had four clusters. Cluster one was on GST curriculum content reflected on the entrepreneurship skills; cluster two was based on the skills the students were exposed to; cluster three was on the skills the students were ready to practice after graduation, and cluster four was based on the challenges to practicing the skills. The instrument was face validated by two experts in GST unit of the university, and one in Measurement and Evaluation, all in Ebonyi State University, Abakaliki. The reliability of the instrument was determined using Cronbach Alpha, and it yielded a coefficient of 0.72 , which was considered high enough to make the instrument reliable for the study.

\subsection{Administration procedure/Analysis Pattern:}

Four hundred (400) copies of the instrument were administered to the sampled respondents, and 349 copies were properly filled that was now used for the study (90\% return was achieved). The data were analyzed using mean $(\bar{X})$ scores and percentages. Any item with a mean rating of 3.00 and above was accepted as entrepreneurial skills provided for in the GST curriculum, or as skills to be adopted for self reliance after graduation, depending on the research question.

\section{Results}

7.1 Research Question 1: To what extent do GST curriculum contents provide for the general entrepreneurship skills/trade?

Table 1 presents the data that answered research question 1.

Table 1: Extent to which GST curriculum contents provide for general entrepreneurship skills. $\mathbf{n}=\mathbf{3 4 9}$

\begin{tabular}{c|l|c|c|c|}
\hline S/N & \multicolumn{1}{|c|}{ Item Description } & $\overline{\mathbf{x}}$ & SD & Remarks \\
\hline 1. & ICT skills & 2.43 & 1.59 & Low Extent \\
2. & Business management/organizational skills & 3.11 & 1.43 & Moderate Extent \\
3. & Marketing skills & 2.65 & 1.48 & Low Extent \\
4. & Communication skills & 2.63 & 1.51 & Low Extent \\
5. & Research skills & 2.70 & 1.58 & Low Extent \\
6. & Personnel management training skills & 2.64 & 1.59 & Low Extent \\
7. & Agricultural development skills & 2.63 & 1.49 & Low Extent \\
8. & Problem solving skills & 2.68 & 1.45 & Low Extent \\
9. & Leadership skills & 2.62 & 1.45 & Low Extent \\
10. & Stress management skills & 2.51 & 1.57 & Low Extent \\
\hline
\end{tabular}

\section{Grand Mean $=2.35$}

Table 1 presents the responses of the students on the extent the GST curriculum contents provide for general entrepreneurship skills. A close look at the table shows that only item 2 which is on business management skills scored above the determinant mean of 3 points, which is 3.11 . The others rated below the 
accepted mean of 3 point thus: item 1 on ICT skills scored 2.43; item 3 on marketing skills scored 2.65; item 4 on communication skills scored 2.63; item 5 on research skills scored 2.70; item 6 on personnel management skills scored 2.64; item 7 on agricultural development skills scored 2.63; item 8 on problem solving skills scored 2.68; item 9 on leadership skills scored 2.62, and item 10 on stress management skills scored 2.51. The grand mean obtained was 2.35 which was below the accepted mean of 3.00 . This now implies that the GST curriculum content does not provide enough of these general entrepreneurships skills for the students' acquisition.

\subsection{Research Question 2: To what extent were you exposed to the specific skills/trade?}

Table 2 presents the data that answered research question 2.

Table 2: Entrepreneurship skills /trade students were exposed to $\quad n=349$

\begin{tabular}{|c|c|c|c|c|}
\hline$S / N$ & Item Description & $\bar{x}$ & SD & Remarks \\
\hline 11. & Soap/detergent making & 2.31 & 1.56 & Low Extent \\
\hline 12. & Tooth brush making & 2.02 & 1.41 & Low Extent \\
\hline 13. & Tooth paste making & 2.13 & 1.38 & Low Extent \\
\hline 14. & Water treatment and packaging & 2.76 & 1.54 & Low Extent \\
\hline 15. & Food processing & 2.78 & 1.52 & Low Extent \\
\hline 16. & Food packaging /preservation & 2.74 & 1.54 & Low Extent \\
\hline 17. & Extraction of vegetable oil & 2.51 & 1.47 & Low Extent \\
\hline 18. & Fish culture methods and techniques & 2.61 & 1.50 & Low Extent \\
\hline 19. & Baking/pastries & 2.70 & 1.60 & Low Extent \\
\hline 20. & Photography & 2.64 & 1.57 & Low Extent \\
\hline 21. & Tailoring and fashion designing & 2.50 & 1.57 & Low Extent \\
\hline 22. & $\begin{array}{l}\text { Animal husbandry-(poultry, piggery, } \\
\text { Sheep/goats, grass cutter farming }\end{array}$ & 2.36 & 1.56 & Low Extent \\
\hline 23. & Crop farming & 2.05 & 1.42 & Low Extent \\
\hline 24. & Mushroom farming & 1.84 & 1.34 & Low Extent \\
\hline 25. & Tanning industry & 1.85 & 1.32 & Low Extent \\
\hline 26. & Printing/publishing & 1.99 & 1.38 & Low Extent \\
\hline 27. & Book-keeping & 2.19 & 1.53 & Low Extent \\
\hline
\end{tabular}

Grand Mean= 2.35

Table 2 is the result of the responses of students on entrepreneurship skills the students were exposed to. Surprisingly, all the item means were below 3.00 the accepted mean thus: item 11 on soap detergent had 2.31 as mean; item 12 on tooth brush making recorded a mean of 2.02; item 13 on tooth paste making had a mean of 2.13; item 14, 15 and 16 on water treatment and packaging; food processing, packing and preservation recorded means of 2.76; 2.78 and 2.74 respectively. Again items 17, 18, 19 and 20 based on extraction of vegetable oil; fish culture methods; baking/pastries and photography had means of 2.51, 2.61, 2.70 and 2.64 respectively. Item 21 was on tailoring and fashion designing which recorded a mean of 2.50; item 22 was on animal husbandry which recorded a mean of 2.36; item 23 based on crop farming recorded a mean of 2.05; mushroom farming recorded a mean of 1.84. Item 25 was on tanning industry which recorded a mean of 1.85, and then items 26 and 27 based on printing /publishing and book keeping recorded means of 1.99 and 2.19 respectively. On the whole, the grand mean was 2.35. It then means that a reasonable number of the students indicated that they have not been exposed to the above stated entrepreneurship skills/trades. 
7.3 Research Questions 3: Which of the entrepreneurship skills/trade are you ready to practice after graduation for self-reliance?

Table 3 presents the data that answered research question 3.

Table 3: Entrepreneurship skills students are ready to practice after graduation. $\quad \mathbf{n}=\mathbf{3 4 9}$

\begin{tabular}{|c|c|c|c|c|c|}
\hline$S / N$ & Item & Yes & $\%$ & No & $\%$ \\
\hline 28. & Soap/detergent making & 165 & 47.3 & 184 & 52.7 \\
\hline 29. & Tooth brush making & 128 & 36.7 & 221 & 63.3 \\
\hline 30. & Tooth paste making & 146 & 41.8 & 203 & 58.2 \\
\hline 31. & Water treatment and packaging & 194 & 55.6 & 155 & 44.4 \\
\hline 32. & Food processing & 230 & 65.9 & 119 & 34.1 \\
\hline 33. & Food packaging /preservation & 180 & 51.6 & 169 & 48.4 \\
\hline 34. & Extraction of vegetable oil & 151 & 43.3 & 198 & 56.7 \\
\hline 35. & Fish culture methods and techniques & 166 & 47.6 & 183 & 52.4 \\
\hline 36. & Baking/pastries & 187 & 53.6 & 162 & 46.4 \\
\hline 37. & Photography & 166 & 47.6 & 183 & 52.4 \\
\hline 38. & Tailoring and fashion designing & 174 & 49.9 & 175 & 50.1 \\
\hline 39. & $\begin{array}{l}\text { Animal husbandry-(poultry, piggery, } \\
\text { Sheep/goats, grass cutter farming }\end{array}$ & 153 & 43.8 & 196 & 56.2 \\
\hline 40. & Crop farming & 137 & 39.3 & 212 & 60.7 \\
\hline 41. & Mushroom farming & 107 & 30.7 & 242 & 69.3 \\
\hline 42. & Tanning industry & 131 & 37.5 & 218 & 62.5 \\
\hline 43. & Printing/publishing & 159 & 45.6 & 190 & 54.4 \\
\hline 44. & Book-keeping & 158 & 45.3 & 191 & 54.7 \\
\hline
\end{tabular}

Table 3 deals with the entrepreneurship skills/trade the students are ready to practice after graduation. A look at the table shows that only 4 items scored above $50 \%$ which is the bench mark namely item 31 on water treatment and packaging that scored 55.6\% (194 respondents) agreed that they could practice the trade on graduation; item 32 that was on food processing scored $65.9 \%$ (230 respondents says yes). Item 33 on food packaging/preservation which scored 51.6\% (representing 180 respondents in agreement, and item 36 on bakery/pastries which scored 53.6\% (187 respondents). The other 13 items had lower percentages as can be seen from the table that accepted that they would practice the various skills on graduation. Based on the findings, majority of the students agree that they could practice most of the skills in the curriculum.

7.4 Research Question 4: To what extent have you perceived possible challenges to practising the entrepreneurship skills/trade after graduation?

Table 4 presents the data that answered research question 4. 
Table 4: Challenges of practicing entrepreneurship skills/trade after graduation. $\quad n=349$

\begin{tabular}{c|l|c|c|c|}
\hline S/N & \multicolumn{1}{|c|}{ Item Description } & $\overline{\mathbf{X}}$ & SD & Remarks \\
\hline 45. & How to make proper planning & 3.39 & 1.56 & Moderate Extent \\
46. & How to make proper budgeting & 3.21 & 1.54 & Moderate Extent \\
47. & Sourcing for take-off funds & 3.18 & 1.53 & Moderate Extent \\
48. & Identifying ready markets for products & 3.16 & 1.50 & Moderate Extent \\
49. & Identifying appropriate business premises & 3.13 & 1.56 & Moderate Extent \\
50. & Facing more experienced competitors & 3.16 & 1.50 & Moderate Extent \\
51. & Taking risks & 2.89 & 1.51 & Low Extent \\
52. & Managing stressful conditions & 2.73 & 1.58 & Low Extent \\
\hline
\end{tabular}

\section{Grand Mean $=3.11$}

Research question 4 sought to find out from the students the possible challenges they would face in practicing the entrepreneurship skills/trade after graduation. Table 4 now presents their responses. A look at the table above shows that items $45-50$ recorded means that are above the decision mean of 3.00 thus: Challenges of making proper planning has mean of 3.37; budgeting challenges recorded a mean of 3.21; sourcing for take off funds had a mean of 3.18; problems of identifying ready markets for products recorded a mean of 3.16; challenges of identifying appropriate business premises has a mean of 3.31 and item 50 which is hinged on facing more experienced competitors recorded a mean of 3.16. On the other hand, the students perceived that they can manage risk taking and stressful conditions in items 51 and 52, with means of 2.89 and 2.73 respectively. Conclusively, the students agree to a reasonable extent that items 45 to 50 would pose considerable challenges to them in practicing the entrepreneurship skills/trade, while perceiving that they can manage stressful conditions and risk taking.

\section{Discussion}

Research question one aimed at ascertaining the extent of provision of entrepreneurship skills/trade in the GST curriculum content. The students agreed that the GST curriculum content of the entrepreneurship skills does not provide for general entrepreneurship skills except for the skill of business management. Nine out of the ten enlisted general skills were not provided for in the curriculum. This agrees with the findings of Oboegbulem and Enyi (2010) that the education system neglects to equip students with useful practical skills that should help them to attain self-reliance and actualization.

Table 2 presents the findings of the study based on the skills the students were exposed to. The study equally found out that all the seventeen specific entrepreneurship skills/trades provided in the curriculum fell below expectation, indicating that a good number of the students were not exposed to these skills. This type of situation creates a big gap between attained curriculum and the planned curriculum. This finding is in line with the assertion of Izuagba and Enwereuzoh (2010) that there should be a close relationship between the planned curriculum and the implemented curriculum, to enable the desired objective to be achieved. Offorma, Egbe and Eze (2012) also emphasized that for the objectives of entrepreneurship education to be achieved, students should be made to acquire the practical skills which would differentiate them from people from other disciplines. In addition to these findings, the researchers observed that many students do not attend lectures regularly. Consequently, they would normally find it difficult to grasp what was taught in their absence. The researchers also noted from discussions with the students that most of these skills/trades were presented to them by lecture method; that there was no practical demonstration of the skills for them.

Table 3 answered research question 3 which was based on the skills the students would like to practice on graduation. A look at the table shows that only 4 out of the 17 items reached the bench mark of $50 \%$, and these items were mainly on consumable goods like water treatment/packaging; food processing; food packaging and preservation and baking/pastries. This is not surprising as students are conversant with these trades around their environment, and some of them, have been practicing them to help in their academic 
endevours. This finding agrees with the assertion of Ogah, Eze, Mbah and Emesini (2009) that students learn best those things that help them to meet real needs, or those things that are related to some active interest. On the other hand, a high percentage of the students were not confident that they would practice the remaining thirteen skills. This could be as a result of non-practicalization of the skills by the lecturers for the students' proper comprehension. In line this finding, Sithole (2009) reiterates that for students to acquire the needed skills that will make them enterprising individuals in the future, they need to acquire specific skills through work related training, experiential teachings and practical methodologies. This involves developing the needed competences to enhanced their skill acquisition, and this must be based on "do it yourself" or 'hands-on-practice' procedure. Again, Izedoni and Okafor (2010) emphasis that entrepreneurship education equips youths with passion and multiple skills, to operate a successful business on their own.

From the findings, the students were not exposed to the practical aspects of most of the skills/trade, and where the practical demonstration is lacking, students do not have confidence to practice on their own; hence the low percentage recorded on skills to be practiced after graduation. For the curriculum to be functional, students have to be equipped with skills that enable them to function as competent and accepted adults in the society (Esu, 2010).

Table 4 presents the analysis on the extent students perceive some challenges to practicing entrepreneurship skills/trade after graduation. The findings show that out of the 8 items, only 2 of them scored a little below the expected mean of 3.0. This simply portrays that the students believe that they are going to face these enlisted challenges in the practice of their own business after graduation. This is not surprising as the students were not exposed to the practice of the skills/trade; hence they do not have the confidence to face the involvements. Backing up these findings, Duru (2008) posits that learners are prepared to demonstrate commitment and interest in their vocational areas, and that once this is done, they are self-motivated, responsible, flexible and adaptable to changes that would profit them. In the process, they develop the essence of risk taking, goal setting, initiative and entrepreneurial abilities. Furthermore, Dakare et al (2011) emphasize that entrepreneurship involves the ability to turn idea into action, which includes creativity, innovation and risk taking, as well as the ability to plan and manage projects in order to achieve the desired objectives.

\section{Conclusion}

The study x-rayed the entrepreneurship programme in Nigerian universities, challenges and the way forward. The findings showed that the students were not practically exposed to the entrepreneurship skills and the link between the general curriculum and the specific skills. Again, the students were taught these skills theoretically, and were not exposed to the practical aspects (hands-on-practice). As a result, a large percentage of them could not opt to practice most of the skills on graduation. Finally, the students perceived that there are obvious challenges they would face in the practice of the skills/trade. With proper training and guidance, the students would overcome these challenges and become successful entrepreneurs that would train and employ others.

\section{Recommendations}

Based on the findings of the study, the following recommendations are made:

- The essence and content of the general entrepreneurship curriculum, and the link to the specific skills should be made clear to the students during training;

- Experts in the various specific skills/trade should be employed to train and re-train all the lecturers that handle entrepreneurship education for better outputs;

- Enough financial and material resources should be made available to the universities for detailed practilization of the courses, to make them exciting and interesting to the students; 
- One year period of internship for university students should be instituted. This internship period should be done in well established entrepreneurial centres under the supervision of experts there;

- Student- entrepreneurs should be properly trained on the challenges of establishing their business, and how to overcome them, and

- Refundable soft take-off loans should be granted to the new graduate entrepreneurs, to help them consolidate their business.

\section{References}

Adejimola, A.A \& Tayo-Olajubutu, O. (2009). Spinning of an Entrepreneurship Culture among Nigerian University Students: Prospects and Challenges. African Journal of Business Management, 3(3), 080-088.

Dan'Azumi, K. (2010). The Role of Entrepreneurship in Nigerian Economic Development. Academic Scholarship Journal of National Association for Research Development, 2 (3), 71-77.

Dakarie, O., Osifila, G.I. \& Ogbjafor, B.E.A. (2011). Entrepreneurship in Nigerian Universities Curriculum: A Strategic Tool for Reduction of Unemployment and Economic Growth. Journal of Academic Excellence of National Association for the Advancement of Knowledge (NAFAK), 3(3), 8-19.

Duru, V. N. (2008). Integrating ICT. Resources and Application in Teaching and Learning of Integrated Science: Towards Development of a Total Person. Paper Presented at the 21st Annual Conference of Curriculum Organization of Nigeria (CON) held at NERDC - Sheda, Abuja.

Egwu, U.E.; Ogbu, O.; Ogunji, J.; Oselebe, H. \& Ama, A.U. (eds.) (2011).Entrepreneurship and Intrapreneurship: Principles and Practice (A book of Readings). Ebonyi State University Press.

Ekong, A.O. \& Williams, P.S. (2006). Entrepreneurship Education in Nigeria and its Implications for Manpower Needs of the Nation. An International Journal of the Teachers Registration Council of Nigeria, Abuja (TRCN), 1(3), 112-120.

Esu, A.E.O. (2010). Functionality of Curriculum in Nigeria. WCCI Seminar Series, (no.5), Held at University of Nigeria. Nsukka on October.

Giwa, R .F. (2000). Investment and Trade Opportunities: Towards Economic Revival. A paper Presented at a Seminar on Nigeria at 40 September held at Abuja from $27^{\text {TH }}$ September- October $2^{\text {nd }}$.

Hornby, A.S. (2000). Oxford Advanced Learners Dictionary of Current English. London: Oxford University Press.

Izedoni, P.F. \& Okafor, C. (2010). The Effect of Entrepreneurship Education on Students' Entrepreneurial Intention. Global. Journal of Management and Business Research, 10(6), 49-60.

Izuagba, A \& Enwereuzoh, N.M. (2010). Entrepreneurial Skills in English Language Teacher Education Curriculum. International Journal of Educational Research, 11(3), 172-179.

Nworgu, B.G. (2006). Educational Research: Basic issues and methodology. Owerri: Wisdom Publishers.

Oboegbulem, A.I. \& Enyi, D. (2010). Staff Development for Improved Youth Entrepreneurship Education. International Journal of Educational Research, 10(3), 10-23.

Offorma, G.C., Egbe, C. I. \& Eze, K.O. (2012). Analysis of Entrepreneurial Skills Acquisition Content of Language Education Curricula at the University of Nigeria. Nigerian Journal of Curriculum Studies, 19 (3), 94-101.

Ogah, M.E.U.; Eze, P.I.; Mbah, B.A. \& Emesini, N.O. (2009). Fundamentals of Curriculum Development, Implementation and Instruction. Enugu: SNAAP Press (Nig.) Ltd.

Okojie, J.A. (2008). Policy Framework and Strategy for Entrepreneurship Development for Nigerian Universities. A Paper Presented at the National Sensitization Workshop on Entrepreneurship Development in Nigerian Universities Organized by NUC at Abuja on $21^{\text {st }}$ May.

Okojie, J.A. (2011). Introductory Speech of the Executive Secretary of NUC on Undergraduate Programme for GST Entrepreneurship held at Abuja on February.

Onyekwelu, V.C. (2005). Skills Development and Acquisition for Effective Universal Basic Education Scheme. Journal of Counselling and Communication (JCC) of Anambra Counselling Association of Nigeria, Anambra State, 1(2), 118125.

Osibanjo, O. (2006). Concept of entrepreneurship. A Paper Presented at the Workshop on Entrepreneurship and Innovation for 200 Level Students in University of Ibadan on18th January. 
Schumpeter, J.A. (1934). The Theory of Economic Development: An Inquiry into Profits, Capital, Credit, Interests and Business Cycle. Cambridge, MA: Harvard University Press. 